\title{
Ending the medicalization of female genital mutilation/cutting in Egypt
}

Sarah Ghattass

Nahla G. Abdel-Tawab

Population Council

Salma Abou Hussein

Population Council

Follow this and additional works at: https://knowledgecommons.popcouncil.org/departments_sbsr-rh

Part of the Demography, Population, and Ecology Commons, Family, Life Course, and Society Commons, International Public Health Commons, Maternal and Child Health Commons, Sociology of Culture Commons, and the Women's Health Commons How does access to this work benefit you? Let us know!

\section{Recommended Citation}

Ghattass, Sarah, Nahla G. Abdel-Tawab, and Salma Abou Hussein. 2016. "Ending the medicalization of female genital mutilation/cutting in Egypt," Policy brief. Cairo: Population Council. 


\section{Ending The Medicalization of Female Genital Mutilation/ Cutting In Egypt}

Sarah Ghattass, Nahla Abdel-Tawab, Salma Abou Hussein

\section{INTRODUCTION}

Despite the presence of a law banning female genital mutilation/cutting (FGM/C), the practice continues to be widespread in Egypt. According to 2014, Egypt Demographic and Health Survey (EDHS), the prevalence of $\mathrm{FGM} / \mathrm{C}$ is $93 \%$ among ever-married women aged 15-49 (MOHP, ElZantay and Associates, and ICF International, 2015). Type I (i.e. partial or total removal of the clitoris and/or the prepuce) and type II (i.e. partial or total removal of the clitoris and the labia minora, with or without excision of the labia majora) are the most common types of FGM/C in Egypt (WHO, 2008; Tag-Eldin et al., 2008). Reasons underlying the practice of $\mathrm{FGM} / \mathrm{C}$ include believing it is a religious requirement; it protects a girl's chastity/ prevents against adultery or husbands prefer women who are circumcised (MOHP, El-Zanaty and Associates and, ICF International, 2015; Tag-Eldin et al., 2008).

According to the 2014 Survey of Young People in Egypt (SYPE) ${ }^{1}$, the prevalence of FGM/C tends to be declining among younger generations of women (73.9\% amongst females age 13-17 compared to $85.7 \%$ amongst those age 30-35). However, more parents are relying on medical personnel to circumcise their daughters (Ismail, Abdel-Tawab \& Sheira, 2015). It is noteworthy that rates of FGM/C medicalization (i.e. performance of the practice by medical personnel) in Egypt are more extensive than in any other country where FGM/C is practiced (UNICEF, 2013).

Medicalization of a harmful practice such as FGM/C institutionalizes and normalizes it, making the process of complete abandonment more difficult (Askew et al., 2016). A global strategy to stop health-care providers from performing FGM/C was developed by the World Health Organization (WHO) and in collaboration with multiple governments, health-care professional bodies, UN agencies and non-governmental organizations (NGOs) after recognizing the magnitude of the problem (WHO, 2010). It is a call to action by which supportive legal and educational frameworks are created and implemented, monitoring and accountability channels are strengthened and capacities of healthcare providers are improved.

1 SYPE was conducted by the Population Council in collaboration with the Central Agency for Public Mobilization and Statistics (CAPMAS). It is a nationally representative survey conducted with more than 10,000 young people in 2009 and 2014. It provides a comprehensive profile of Egyptian adolescents and youth before and after the 2011 and 2013 political events.

\section{KEY MESSAGES}

1. Even though the percentage of young girls who were exposed to female genital mutilation / cutting (FGM/C) is declining, there is a steady increase in the percentage of girls who were cut by a medical doctor or a nurse.

2. Mothers seek medical personnel as they are more trusted and are believed to be better trained to deal with any complications.

3. Social marketing campaigns that focus on immediate health risks of FGM/C may indirectly lead to medicalization of $\mathrm{FGM} / \mathrm{C}$.

4. Multifaceted interventions targeting medical personnel and the public are needed to end both the supply and the demand for FGM/C.

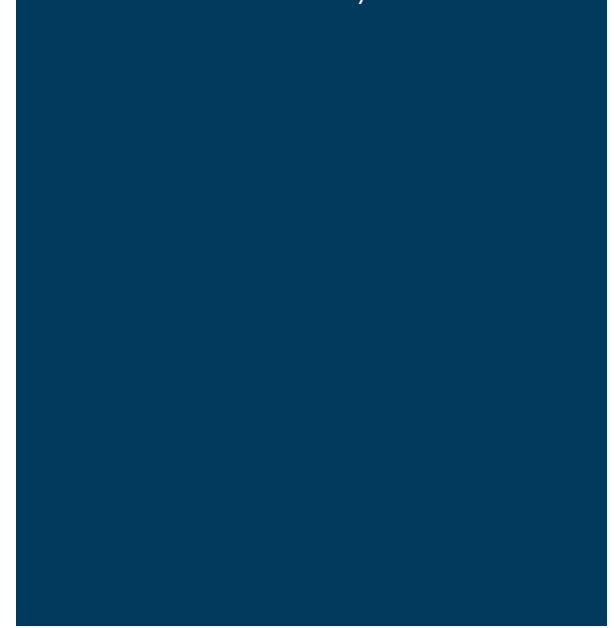

POPULATION COUNCIL

Ideas. Evidence. Impact. 
In this policy brief, we examine the extent of medicalization of FGM/C in Egypt, the characteristics of girls who were cut by medical personnel, factors that may have contributed to increased medicalization, and potential interventions that could influence both physicians and the public to completely abandon the practice. Data used in this brief are based on review of relevant literature, secondary analysis of SYPE 2014 data, and a round table discussion with key stakeholders in Egypt.

\section{Which groups of Women Are Cut by Medical}

\section{Personnel?}

Understanding the characteristics of young women who are cut by medical personnel is important for desgining targeted and effective interventions to accelerate abandonment of this practice. According to SYPE 2014, $80.5 \%$ of young women age 13-35 had been exposed to FGM/C (Ismail, Abdel-Tawab \& Sheira, 2015). Of those women, $55.3 \%$ reported that they were cut by a physician or nurse (43.8\% and $11.5 \%$ respectively). A closer look at the data shows that younger women were more likely to be cut by medical personnel compared to older women (Figure 1), meaning, medicalization of FGM/C has increased over the past few generations.

FIGURE 1. Percent distribution of type of FGM/C practitioner among various age groups of young women

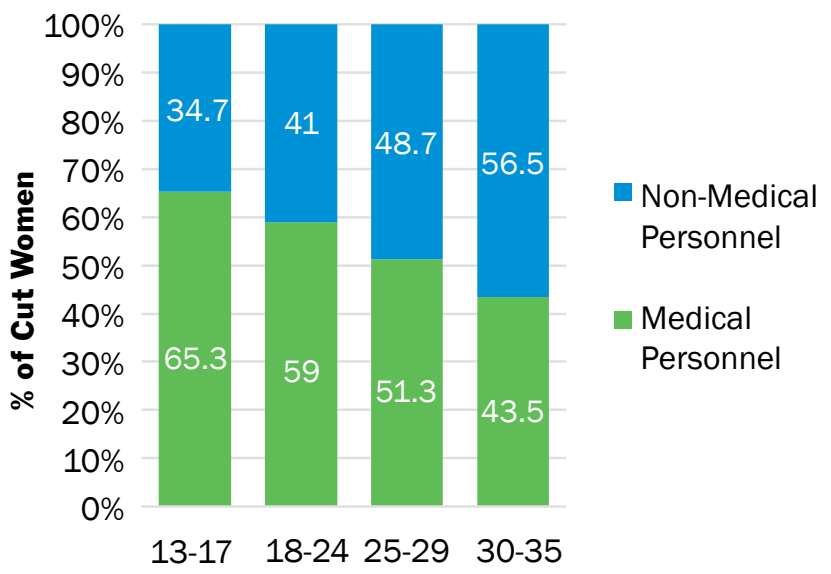

\section{Age Group}

Source: SYPE, 2014

Higher income levels were also associated with higher medicalization rates. Nevertheless, $43 \%$ of young women from the lower quintiles whose parents may not have had the financial means were cut by medical personnel, compared to $71 \%$ of women in the highest wealth quintile (Figure 2). Given the correlation between wealth and education, it is not surprising that women who obtained a higher level of education were more likely to have been cut by medical personnel; more than $70 \%$ of women who obtained a general secondary school certificate or higher were cut by medical personnel (data not shown). Moreover, medicalization of FGM/C is common in all regions of Egypt, but more common in urban areas: $49-52 \%$ in rural areas and frontier governorates and above $62 \%$ in urban areas of Egypt (data not shown).

FIGURE 2. Percent distribution of type of FGM/C practitioner among various wealth quintiles of young women

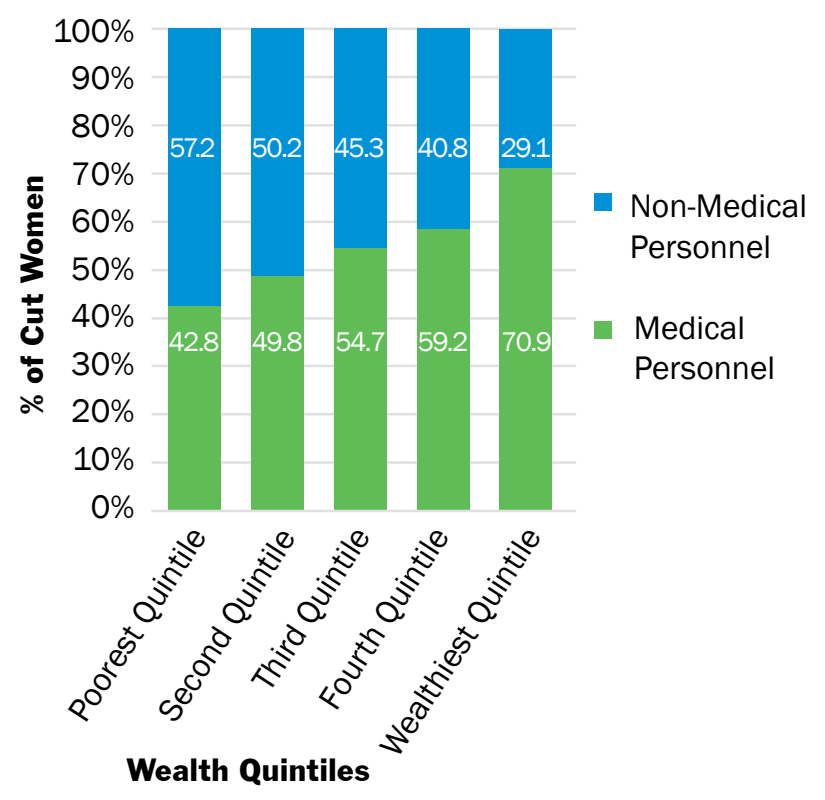

Source: SYPE, 2014

\section{Why Do Mothers Prefer Going to Medical Personnel for FGM/C?}

A recent study that examined medicalization of FGM/C from mothers' perspectives in Qalyubia (Modrek \& Sieverding, 2016) found that more than $30 \%$ of mothers were uncertain about cutting their daughters. These mothers intended to seek a physician's opinion to determine whether their daughters "needed" FGM/C. Most mothers expressed a high level of trust in physicians' opinions. Moreover, out of the mothers who were certain about cutting their daughters, about $90 \%$ intended to have a physician perform the cutting. Mothers believed that physicians, compared to dayas, are better trained to deal with any complications, such as hemorrhage (Modrek \& Sieverding, 2016; UNICEF, 2013).

\section{Current Attitudes and Behaviors of Physicians}

There are scarce studies that have examined physicians' attitudes or behaviors with regard to FGM/C. However, the few available studies along with the widespread 
medicalization suggest that a substantial percentage of physicians may be supportive of the practice. In a study that involved a self-administered questionnaire delivered to 193 physicians via e-mail 19\% of physicians reported practicing FGM/C. Half of those physicians believed in benefits of FGM/C; 30\% practiced for financial gains while $19 \%$ believed that they were reducing harms that could result from performing the procedure by a daya (Refaat, 2009).

The above-mentioned study of mothers in Qalyubia (Modrek \& Sieverding, 2016) illustrated that some physicians were indifferent about FGM/C, while others believed that there are medical reasons for performing FGM/C. Physicians would commonly examine young girls and determine whether they "needed" FGM/C. Some would ask mothers to bring their daughters to be reexamined at an older.

\section{Factors that May Have Contributed to Medicalization of FGM/C}

Over the past 20 years several ministerial decrees and interventions may have inadvertently led to medicalization of FGM/C. For example, in 1994 a ministerial decree legalized the practice in designated medical facilities (Barsoum et al., 2009), implying that the practice is not harmful if performed by a physician. In 1997, another ministerial decree banned FGM/C except when "medically necessary" (Modrek \& Liu, 2013). Consequently, this decree gave physicians the final say in deciding if FGM/C was necessary. It was not until 2007 that the MOHP completely banned FGM/C and, in 2008, FGM/C became punishable by law (Hassanin et al., 2008).

However, banning FGM/C did not stop physicians from practicing it and did not decrease the demand for FGM/C because the law is barely enforced. Many physicians reportedly do not know about the law or do not consider FGM/C to be a serious violation (Refaat et al., 2001). Some may not fear getting punished because they see other physicians practice and go unpunished. For example, the physician who was tried for the death of Soheir El Bataa in 2013 was not convicted until 2015 (Khaleefa, 2015). Even though he received a two year sentence and thus, his medical license was revoked afterwards, there were reports that he continued to practice medicine (Fadel, 2015).

Along with weak enforcement of the law, lack of education of physicians on FGM/C in medical schools increased support for the practice among physicians. A survey of medical students found that $41 \%$ of students have poor knowledge of the complications of FGM/C (Refaat et al., 2001). A quick review of medical school curricula showed that some Obstetrics and Gynecology (Ob/Gyn) notes which medical students study from include inaccurate information about FGM/C. For example, notes from a reputable university in Cairo state the following indications for cutting 'large' labia: nymphomania (increased sexual desire), dyspareunia (painful sexual intercourse), and for cosmetic reasons." Moreover, most medical schools do not cover FGM/C in their curricula, and when FGM/C is included in medical school books, professors rarely address the topic. Thus, it is clear that there is a great 'knowledge barrier' that prevents physicians from ending the practice of FGM/C.

Furthermore, media campaigns may have played a role in increasing medicalization of FGM/C. Previous media campaigns often focused on immediate health complications of FGM/C, specifically bleeding, infection and death (Shell-Duncan, 2008). Thus, parents, focusing on immediate health complications and being unfamiliar with long-term complications, increasingly opted for medical personnel (Modrek \& Sieverding, 2016).

Finally, Muslim religious leaders' standpoint vis a vis FGM/C was not made clear until recently. Up until 2006, both prominent sheikhs Muhammad Sayyid Tantawy and Yusuf Al-Qaradawi stated that parents should refer to physicians in regards to FGM/C (Al-Qaradawi, 2007; BBCArabic, 2006). They also stated that FGM/C could not be forbidden if a physician performs the procedure. Fortunately, they have altered their stance on FGM/C. Moreover, Al-Azhar recently released a fatwa forbidding FGM/C and justifying efforts to fight the practice (Ali, 2016).

\section{Conclusion}

Secondary analysis of SYPE 2014 shows that younger cohorts of women, those from higher wealth quintiles, higher levels of education, and living in urban regions are more likely to have been cut by medical personnel. More importantly, the analysis shows that despite medicalization being more common among young women with the above-mentioned characteristics, it is in fact prevalent among all groups of young women and in all regions of Egypt.

Medicalization of FGM/C in Egypt persists largely due to physicians' supporting and performing the practice. 
Furthermore, multiple factors may have led to the medicalization of FGM/C which include the weak law enforcement and the focus of social marketing campaigns on immediate health complications. Thus, it is unlikely that interventions will be effective unless those factors are addressed.

\section{Policy Recommendations}

In order to end the practice of FGM/C, interventions must aim to stop physicians from performing FGM/C, while correspondingly aiming to decrease the demand of the public for FGM/C. Additionally, interventions must address underlying cultural and religious norms that perpetuate the practice of FGM/C.

Studies show that combining bottom-up approaches with top-down approaches yields more successful results (Robertson \& Jochelson, 2006). Therefore, we recommend multifaceted interventions that target physicians, direct beneficiaries, the community, and national institutions (Mostofian et al., 2015). Physicianlevel interventions should aim to change physicians' attitudes and behaviors towards FGM/C. Direct beneficiaries-level interventions should target young girls, parents, and youth, with the goal of decreasing the demand for FGM/C. Community-level interventions should focus on addressing underlying reasons for the practice of FGM/C such as gender and religious norms while national-level interventions should focus on law enforcement and policy reform.

\section{Educate physicians about FGM/C}

\section{RECOMMENDATION 1}

Integrate FGM/C into medical school curricula;

inform students about its complications, its

illegality, and teach them how to properly counsel

mothers against FGM/C.

Previous interventions often focused on training physicians through workshops and seminars or through other means of raising awareness. The above training was sometimes associated with notifying physicians about the law against FGM/C or incentivizing physicians to join the fight against FGM/C by offering them accreditation. Training physicians is costly, and thus its sustainability is limited. A more sustainable and effective intervention is integrating material on FGM/C into medical school curricula, preferably into the gynecology course (Edouard et al., 2013). Material on FGM/C should include short- and long-term complications and how to counsel women about FGM/C. Such material could also be integrated in pre-service training of MOHP physicians. Additionally, medical ethics courses could emphasize that practicing FGM/C breaks the Hippocratic oath, which entails to "first, do no harm" (Edouard et al., 2013; Serour, 2013; Askew et al., 2016). A mandatory question on FGM/C in the final exam would ensure that professors will cover the material and that students will study it.

The MOHP in partnership with the Ministry of Higher Education (MOHE) and the Supreme Council for Universities had previously created a committee responsible for implementing the above-mentioned recommendations. However, change in leadership and the structure of MOHP brought the committee's work to a halt. Opportunely, in February 2016, the Deputy Minister for Population, Dr. Maysa Shawky announced a new initiative titled "Doctors against FGM/C" under the sponsorship of the National Population Council. This initiative confirms political commitment towards fighting the medicalization of FGM/C. It is hoped that the Deputy Minister will adopt this issue and reinstate the committee. Such an initiative can disseminate a statement condemning FGM/C in collaboration with the Medical Syndicate as well as Ob/Gyn Society at annual Ob/Gyn seminars and conferences.

If future interventions succeed at having physicians join the fight against FGM/C such that they not only refuse to practice $\mathrm{FGM} / \mathrm{C}$, but also counsel women against the practice, many undecided women could choose to not cut their daughters. Furthermore, given the high trust mothers have in physicians' opinions, a large percentage of mothers who are determined to cut their daughters may reconsider their decision if the physician is persuasive enough and is able to address the mother's concerns about abiding to religious teachings or protecting their daughters' chastity.

\section{Reduce Public Demand for FGM/C}

\section{RECOMMENDATION 2}

Educate religious leaders on the complications

of FGM/C, and broadcast the recent fatwa that forbids FGM/C. Additionally, reshape gender norms by changing youth attitudes. 
In order to effectively solve the problem of medicalization and eventually end the practice, interventions must aim to decrease the demand for FGM/C by targeting the public. Interventions are more effective when they move from raising awareness to behavior change by addressing the underlying reasons for practicing FGM/C (Edouard et al., 2013; Robertson \& Jochelson, 2006).

To truly reshape societal norms, interventions must invest in youth, because they are the most amenable to change and they are the future parents. Therefore, we recommend integrating material on inequitable gender norms and the harms of FGM/C in school curricula (Berg \& Denison, 2012; Varol et al., 2015). Also, we recommend designing school campaigns in which trained individuals motivate youth to take a stance against FGM/C. These campaigns could adopt peerto-peer education techniques, which are believed to be highly acceptable amongst youth (Sriranganathan et al., 2012). Likewise, similar campaigns could more specifically target young girls through empowering them with information and skills to stop FGM/C from being inflicted on them (e.g. by calling the Child Help hotline) (Berg \& Denison, 2012).

The underlying reasons for FGM/C mostly root from religious misconceptions and commonly held inequitable gender norms. Targeting religious leaders starting from prominent imams in villages to prominent sheikhs in urban cities is important, because people often refer to them for guidance (Edouard et al., 2013; Berg \& Denison, 2012). Besides holding workshops, we recommend promoting Al-Azhar as the one authoritative reference for the public concerning religious matters. Moreover, it is important to publicize the recently released fatwa ${ }^{2}$ forbidding FGM/C and condoning efforts to stop the practice by including it in social marketing campaigns against FGM/C and through dissemination at annual Ob/Gyn conferences and seminars.

Besides targeting religious leaders, the public, and youth, it is crucial to publicize the new shift in norms. The public needs to know that new norms have replaced the old ones and that the whole community approves the new norms. This can be achieved through holding public declarations (Diop et. al, 2008; Barsoum et al., 2009). The latter relieve community pressure so that parents will not fear being stigmatized by their communities for abandoning a deeply- rooted tradition (Varol et al., 2015).
Complement Interventions with a Social

Marketing Campaign

\section{RECOMMENDATION 3}

Invest in a social marketing campaign that takes advantage of both traditional and social media.

Social marketing campaigns, when combined with other interventions, can be very effective in changing physicians' and the public's behaviors (Edouard et al., 2013; Robertson \& Jochelson, 2006). Despite the high cost of a media campaign, it makes up for its cost by reaching a much wider audience compared to any other intervention (Paluck et al., 2010). Moreover, the government could negotiate with popular television channels to lower prices for airing anti-FGM commercials, or it could pass a law that obligates channels to air public health messages as part of their corporate social responsibility. We recommend investing in creating a social marketing campaign that delivers a strong behavior-changing message. Based on studies, campaign messages could :be stronger and more effective if they

- Use opinion leaders such as prominent physicians (Robertson \& Jochelson, 2006).

- Promote physicians to counsel women, not just refuse to practice $\mathrm{FGM} / \mathrm{C}$.

- Refrain from publicizing that many physicians perform FGM/C or that many women are cut , because these messages adversely reinforce the undesired norm. Instead, messages should convey the desirable behavior by highlighting the positive examples of physicians and women who are refusing FGM/C (Paluck et al., 2010).

- Make messages relevant to the decision-making moment by portraying the moment when a mother decides to cut her daughter or when a physician accepts to do the procedure (Paluck et al., 2010).

- Motivate physicians and the public to be involved and to report physicians who practice FGM/C (Paluck et al., 2010).

- Focus on long-term complications of FGM/C, depicting its psychological complications and its negative effect on marital relations. 
Use of social media and smart phones applications could also be very effective in reaching younger generations. Internet usage has increased by $15 \%$ in the past two years alone (Alaa El-Din, 2015). Periodic newsletters sent via email or through social media could successfully reach a large percentage of young physicians. Campaigners could take advantage of already popular Internet communities (e.g. Facebook pages) by sending anti-FGM messages through their platforms. Similarly, the usage of smart phones (Alaa El-Din, 2015) could be further maximized through an application created to send physicians reminders about public health issues, including FGM/C

\section{Strengthen Law Enforcement}

\section{RECOMMENDATION 4}

Enforce the law by informing judges on the law against FGM/C and by prompting the medical syndicate to take punitive measures against physicians who practice FGM/C.

Studies show that national-level interventions are necessary in order to complement individual-targeting interventions and create an effective change in physicians' behavior (Robertson \& Jochelson, 2006). NGO officials report that their reports about doctors practicing FGM/C are often not taken seriously by police officers or district attorneys. Also, cases that suffer complications from FGM/C often pass undocumented by forensic medical doctors. Police officers, district attorneys and judges should receive training on the long-term risks associated with FGM/C and the legal and human rights violations that are associated with it. Forensic medical doctors should be trained in identifying and documenting complications associated with FGM/C. Moreover, the medical syndicate should take punitive measures against physicians who practice FGM/C by revoking their license immediately. Furthermore, media coverage could highlight cases of convicted physicians and spread news that the law is indeed enforced.

\section{Law Reform}

\section{RECOMMENDATION 5}

A new law should criminalize physicians alone without criminalizing parents of cut girls.
In a recent positive step, the Law No. $126^{3}$ of 2008 was amended to Law No. 87 of 2016 which considers FGM/C a felony, not a misdemeanor. This amendment may serve as deterrent to doctors who perform FGM/C. However, this law continues to criminalize parents who subject their daughters to FGM/C. Consequently, when a girl suffers from complications of FGM/C or dies, the parents fear to report her death, and thus, the physician goes unpunished (EIPR, 2016). The new law should therefore criminalize the physician alone in order to encourage parents to report physicians who have cut and harmed their daughters.

\section{Clarify and Strengthen the Reporting Mechanism}

\section{RECOMMENDATION 6}

Enhance the current reporting mechanism and support the Private Sector Department at MOHP in investigating claims against doctors practicing FGM/C. Also, collaborate with non-governmental organizations (NGOs) to report cases of FGM/C.

The current reporting mechanism could benefit from some clarification and simplification, such that the public become aware to report all cases to one source: the Child Help hotline (16000). Media campaigns should publicize this hotline while prompting the public and physicians to report other physicians who practice FGM/C.

The Private Sector Department at MOHP receives reports related to FGM/C from the Child Help hotline. One officer is then sent to investigate the claim without any back up from the police. We recommend training the already established 'anti-violence' police force, which specifically deals with gender-based violence and child abuse cases, to also deal with FGM/C reports and backup the Private Sector Department team. Furthermore, the Private Sector Department which is composed of a very small number of officers could benefit from support provided by other MOHP sectors to deal with the numerous cases of FGM/C.

3 Child law number 126 in 2008, article 262: “And without prejudice to any more severe penalty provided for in another law, shall be punished by imprisonment for not less than three months and not exceeding two years, or a fine of not less than one thousand pounds and not exceeding five thousand pounds, anyone who has created a wound by performing female genital mutilation/cutting" 
In order to further intensify efforts to arrest physicians who practice FGM/C, MOHP could collaborate with NGOs encouraging them to periodically survey villages and report physicians known to perform FGM/C.

\section{Further Studies}

\section{RECOMMENDATION 7}

Employ innovative methodologies in order to investigate why physicians practice FGM/C and how to end this practice.

There is a clear lack of literature on current physicians' attitudes and behaviors in regards to practicing FGM/C. It is important to further investigate the underlying reasons behind physicians' involvement in the practice of $\mathrm{FGM} / \mathrm{C}$.

The Population Council (PC)-Egypt Office is addressing some of the above-mentioned research gaps to inform policy and practice through a series of research studies funded by UK Department for International Development (DFID). It is hoped that results of those studies will contribute to more effective policies and programs to accelerate abandonment of this harmful traditional practice in Egypt and globally.

\section{REFERENCES}

Alaa El-Din M. 2015, April 7. Slight increase in number of internet users last December. Daily News Egypt. Retrieved from http://www.dailynewsegypt. com/2015/04/07/slight-increase-in-number-ofinternet-users-last-december/

Al-Qaradawi Y. (2007, June 26). Ruling on Circumcision (in Arabic). Retrieved June 24, 2016, from http:// www.qaradawi.net/new/Articles-1434

Ali L. 2016, June 3. House of Fatwa: Female genital mutilation is contrary to the Islamic law and the law (in Arabic). Youm7. Retrieved from http://s.youm7. $\mathrm{com} / 2744960$

Askew I, Chaiban T, Kalasa B, Sen P. 2016. A repeat call for complete abandonment of FGM. Journal of medical ethics, medethics-2016.

Barsoum G, Rifaat N, El-Gibaly O, Elwan N, Forcier N. 2009. Toward FGM-Free Villages in Egypt: A Mid-Term Evaluation and Documentation of the FGM-Free Village Project. Cairo: Population Council.
BBCArabic. 2006, November 23. Muslim Scholars Condemn FGM/C (in Arabic). BBC Arabic. Retrieved from http://news.bbc.co.uk/hi/arabic/sci_tech/ newsid_6176000/6176364.stm

Berg RC, Denison E. 2012. Effectiveness of interventions designed to prevent female genital mutilation/cutting: A systematic review. Studies in family planning, 43(2):135-46.

Diop NJ, Moreau A, Benga H. 2008. Evaluation of the Long-term Impact of the TOSTAN Programme on the Abandonment of FGM/C and Early Marriage: Results from a qualitative study in Senegal: Population Council.

Edouard E, Olatunbosun O and Edouard L. 2013. International efforts on abandoning female genital mutilation. African Journal of Urology, 19(3), pp.150-153.

Egyptian Initiative for Personal Rights. 2016. Towards a More Effective Enforcement of the FGM/C Criminalization Law. Position Paper. Cairo: EIPR.

El-Zanaty F, Hussein EM, Shawky GA, Way AA, Kishor S. 1996. Egypt Demographic and Health Survey 1995. Calverton, Maryland [USA]: National Population Council [Egypt] and Macro International Inc.

Fadel L. 2015. Egyptian Doctor Found Guilty of Female Genital Mutilation Isn't In Jail. US National Public Radio.

Hassanin IMA, Saleh R, Bedaiwy AA, Peterson RS, Bedaiwy MA. 2008. Prevalence of female genital cutting in Upper Egypt: 6 years after enforcement of prohibition law.

Reproductive Biomedicine Online, 16:27-31.

Ismail S, Abdel-Tawab N, Sheira L. 2015. Health of Egyptian Youth in 2014: Knowledge, Attitudes, and Behaviors in Panel Survey of Young People in Egypt 2014: Generating Evidence for Policy, Programs, and Research. Cairo: Population Council.

Khaleefa D. 2015, January 27. First time in Egypt: Two year jail sentence for doctor that caused death of a girl during khitan...and three years suspended for father (in Arabic). Al Ahram. Retrieved from http:// www.ahram.org.eg/NewsQ/356555.aspx

Ministry of Health and Population [Egypt], El-Zanaty and Associates [Egypt], and ICF International. 2015. Egypt Demographic and Health Survey 2014. Cairo, Egypt and Rockville, Maryland, USA: Ministry of Health and Population and ICF International. 
Modrek S, Liu J X. 2013. Exploration of pathways related to the decline in female circumcision in Egypt. BMC Public Health, 13(1), 921.

Modrek S, Sieverding M. 2016. Mother, Daughter, Doctor: Medical Professionals and Mothers' decisionmaking about Female Genital Mutilation/Cutting in Egypt. Studies in Family Planning, 47(2), pp. 111202.

Mostofian F, Ruban C, Simunovic N, Bhandari M. 2015. Changing physician behavior: what works? The American journal of managed care, 21(1):75-84.

Paluck EL, Ball L, Poynton C, Sieloff S. 2010. Social norms marketing aimed at gender based violence: $A$ literature review and critical assessment. New York: International Rescue Committee.

Refaat A. 2009. Medicalization of female genital cutting in Egypt. Eastern Mediterranean Health Journal, 15(6), 1379-1388.

Refaat AH, Dandash KF, Lotfy G, Eyada M. 2001 Attitudes of medical students towards female genital mutilation. Journal of Sex \&Marital Therapy, 27(5):589-91.

Robertson R, Jochelson K. 2006. Interventions that change clinician behaviour: mapping the literature. National Institute of Clinical Excellence (NICE).

Serour Gl. 2013. Medicalization of female genital mutilation/cutting. African Journal of Urology, 19(3):145-9.

Shell-Duncan B. 2008. From health to human rights: Female genital cutting and the politics of intervention. American Anthropologist, 110(2), 225-236.
Sriranganathan G, Jaworsky D, Larkin J, et al. (2012) Peer sexual health education: Interventions for effective programme evaluation. Health Education Journal, 71(1): 62-71.

Tag-Eldin MA, Gadallah MA, Al-Tayeb MN, Abdel-Aty M, Mansour E, Sallem M.

2008. Prevalence of female genital cutting among Egyptian girls. Bulletin of the World Health Organization, 86(4):269-274.

Varol N, Turkmani S, Black K, Hall J, Dawson A. 2015. The role of men in abandonment of female genital mutilation: a systematic review. BMC public health, 15(1):1.

World Health Organization (WHO). 2010.

Global strategy to stop health-care providers from performing female genital mutilation. WHO/RHR/10.9. http://www.refworld.org/ docid/4ca3385b2.html

WHO, OHCHR, UNAIDS, UNECA, UNDP. 2008.

Eliminating Female genital mutilation. An interagency statement. Geneva: WHO

UNICEF. 2013. Female Genital Mutilation/Cutting: A statistical overview and exploration of the dynamics of change. New York: UNICEF.

\section{ACKNOWLEDGEMENT}

We are grateful to the multiple donors who supported the production of this policy brief. Special thanks are also due to participants at the round table discussion who provided insights on more feasible and effective interventions to accelerate the abandonment of $\mathrm{FGM} / \mathrm{C}$ in Egypt.
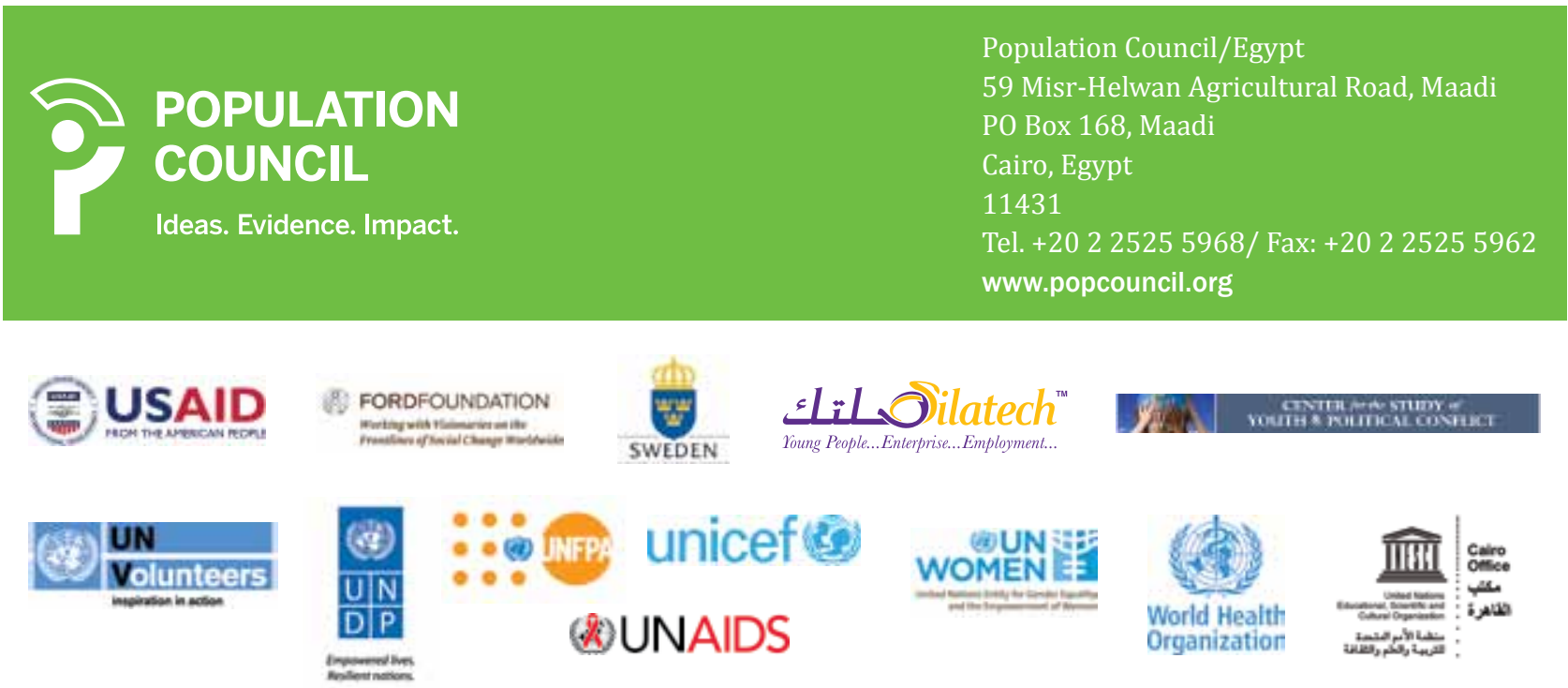